\title{
Sustained Recreational Use of Ecstasy Is Associated with Altered Pre and Postsynaptic Markers of Serotonin Transmission in Neocortical Areas: A PET Study with [ " C]DASB and [ 'C]MDL 100907
}

\author{
Nina BL Urban*, I,4, Ragy R Girgis ${ }^{1,4}$, Peter S Talbot' ${ }^{2}$, Lawrence S Kegeles', X Xu', W Gordon Frankle ${ }^{3}$, \\ Carl L Hart', Mark Slifstein', Anissa Abi-Dargham' and Marc Laruelle' \\ 'Department of Psychiatry, Columbia University, New York State Psychiatric Institute, New York, NY, USA; ${ }^{2}$ Department of Psychiatry, University \\ of Manchester, Manchester, UK; ${ }^{3}$ Department of Psychiatry, University of Pittsburgh, PA, USA
}

\begin{abstract}
3,4-Methylenedioxymethamphetamine (MDMA), the main psychoactive component of the recreational drug ecstasy, is a potent serotonin (5-HT) releaser. In animals, MDMA induces 5-HT depletion and toxicity in 5-HT neurons. The aim of this study was to investigate both presynaptic (5-HT transporter, SERT) and postsynaptic (5- $\mathrm{HT}_{2 \mathrm{~A}}$ receptor) markers of 5- $\mathrm{HT}$ transmission in recently abstinent chronic MDMA users compared with matched healthy controls. We hypothesized that MDMA use is associated with lower SERT density and concomitant upregulation of $5-\mathrm{HT}_{2 \mathrm{~A}}$ receptors. Positron emission tomography studies using the SERT ligand $\left[{ }^{\prime \prime} \mathrm{C}\right] \mathrm{DASB}$ and the $5-\mathrm{HT}_{2 \mathrm{~A}}$ receptor ligand [ ' $\mathrm{C}$ C]MDL 100907 were evaluated in 13 current and recently detoxified MDMA users and 13 matched healthy controls. MDMA users reported a mean duration of ecstasy use of 8 years, regular exposure, and at least 2 weeks of abstinence before the scans. SERT and $5-\mathrm{HT}_{2 \mathrm{~A}}$ receptor availability (binding potential, $\mathrm{BP}_{\mathrm{ND}}$ ) were analyzed with a two-tissue compartment model with arterial input function. Current recreational MDMA use was significantly associated with lower $\mathrm{SERT}_{\mathrm{BP}} \mathrm{ND}_{\mathrm{and}}$ higher $5-\mathrm{HT}_{2 \mathrm{~A}}$ receptor $\mathrm{BP}_{\mathrm{ND}}$ in cortical, but not subcortical regions. Decreased $\mathrm{SERT} \mathrm{BP}_{\mathrm{ND}}$ was regionally associated with upregulated $5-\mathrm{HT}_{2 \mathrm{~A}}$ receptor $B \mathrm{P}_{\mathrm{ND}}$. In light of the animal literature, the most parsimonious interpretation is that repeated exposure to MDMA in humans, even in moderate amounts, leads to damage in 5-HT neuron terminals innervating the cortex. Alterations in mood, cognition, and impulse control associated with these changes might contribute to sustain MDMA use. The reversibility of these changes upon abstinence remains to be firmly established.

Neuropsychopharmacology (2012) 37, I465-1473; do:I0.1038/npp.20II.332; published online 22 February 2012
\end{abstract}

Keywords: MDMA; PET imaging; serotonin markers; [ ' C]MDL I00907; [ ' C]DASB; cortical binding

\section{INTRODUCTION}

The psychoactive component of the popular recreational drug 'ecstasy' is 3,4-methylenedioxymethamphetamine (MDMA). MDMA is used for its distinct positive social and emotional effects (Cohen, 1995). MDMA exerts its effects mainly through direct interaction with the serotonin (5-HT) system, by stimulating 5-HT efflux through binding to and reversal of the 5-HT reuptake transporter (SERT), resulting in increase in synaptic 5-HT levels. In animals, repeated exposure to MDMA is associated with damage to

*Correspondence: Dr NBL Urban, Department of Psychiatry, Columbia University, New York State Psychiatric Institute, I05I Riverside Drive, Unit 31, New York, NY 10032, USA, Tel: + I 212543 6605; Fax: + | 212568 6171, E-mail: nu2118@columbia.edu

${ }^{4}$ These authors contributed equally to this work.

Received 7 September 201 I; revised 28 November 201 I; accepted 16 December 201 I
5-HT neurons at doses overlapping those used by humans (Ricaurte et al, 1985; Schmidt et al, 1986). Decreased density of SERT, exclusively expressed in 5-HT neurons, has been validated as a biomarker of MDMA neurotoxicity in animals (Insel et al, 1989; Ricaurte et al, 1988; Scheffel et al, 1998).

These animal studies raise the serious concern that recreational use of MDMA in humans may result in transient or permanent damage to the 5-HT system, leading to increased vulnerability to mood, anxiety, and impulse control disorders (de Win et al, 2006; Quednow et al, 2007). As the neurotoxic effects of MDMA translate into reduced SERT density, measurement of brain SERT levels in human MDMA users provides an indicator of this presumed toxicity. The ability to image SERT in living humans using the nuclear medicine techniques of single photon emission computed tomography (SPECT) and positron emission tomography (PET) has been slow and difficult to develop, but progress over the last decade has delivered the tools required to address this important issue. 
The first imaging agent detecting SERT in the living brain was the SPECT tracer $\left.{ }^{[23} \mathrm{I}\right] \beta$-CIT (Laruelle et al, 1993). Robust visualization of SERT by $\left[{ }^{123} \mathrm{I}\right] \beta$-CIT is limited to the midbrain, due to its lack of selectivity (Laruelle et al, 1993). Studies with $\left[{ }^{123} \mathrm{I}\right] \beta$-CIT in MDMA users showed inconsistent results (Reneman et al, 2001; Semple et al, 1999). The second imaging agent amenable to visualization of SERT in the living human brain was the PET tracer $\left[{ }^{11} \mathrm{C}\right] \mathrm{McN} 5652$ (Szabo et al, 1995). The first study performed with this ligand reported a major and global decrease in SERT density in MDMA users compared with controls (McCann et al, 1998), a finding that was broadly disseminated in public education campaigns. Subsequent studies performed with $\left[{ }^{11} \mathrm{C}\right] \mathrm{McN} 5652$ by the same US group (McCann et al, 2005), and studies performed in Germany (Buchert et al, 2003; Thomasius et al, 2006) were unable to replicate this dramatic finding, but showed moderately lower SERT binding in some but not all subcortical regions. The limitations of $\left[{ }^{11} \mathrm{C}\right] \mathrm{McN} 5652$ as a SERT imaging agent might account for these discrepancies (Parsey et al, 2000).

More recently, the PET tracer $\left[{ }^{11} \mathrm{C}\right] \mathrm{DASB}$ was developed as a superior agent for SERT imaging (Houle et al, 2000), with significantly improved imaging qualities over $\left[{ }^{11} \mathrm{C}\right] \mathrm{McN} 5652$ (Frankle et al, 2004). Studies of current MDMA users performed with $\left[{ }^{11} \mathrm{C}\right] \mathrm{DASB}$ in Baltimore (McCann et al, 2005, 2008), Toronto (Kish et al, 2010), and Copenhagen (Erritzoe et al, 2011) did not replicate the original $\left[{ }^{11} \mathrm{C}\right] \mathrm{McN} 5652$ finding of a large reduction in SERT density throughout the brain (Szabo et al, 1995), and only one study detected SERT abnormalities in subcortical areas (Erritzoe et al, 2011). However, these $\left[{ }^{11} \mathrm{C}\right] \mathrm{DASB}$ studies consistently showed lower SERT densities in cortical areas. The first aim of the present study was to further document these findings in an independent cohort of current MDMA recreational users.

Sustained damage to 5-HT terminals might also translate into alterations of 5-HT postsynaptic markers. Under certain conditions, chronic 5-HT depletion is associated with upregulation of $5-\mathrm{HT}_{2 \mathrm{~A}}$ receptors (Cahir et al, 2007; Heal et al, 1985). A SPECT study performed with $\left.{ }^{[23} \mathrm{I}\right] \mathrm{R} 93274$ suggested decreased and increased $5-\mathrm{HT}_{2 \mathrm{~A}}$ receptors in current and former MDMA users, respectively (Reneman et al, 2002). A more recent study performed with the PET $5-\mathrm{HT}_{2 \mathrm{~A}}$ radiotracer $\left[{ }^{18} \mathrm{~F}\right]$ altanserin in recently detoxified MDMA users detected no changes in $5-\mathrm{HT}_{2 \mathrm{~A}}$ receptors (Erritzoe et al, 2011). These divergent results might stem from technical limitations of the SPECT tracer $\left[{ }^{123} \mathrm{I}\right] \mathrm{R} 93274$ (Abi-Dargham et al, 1997). The second aim of the present study was to characterize $5-\mathrm{HT}_{2 \mathrm{~A}}$ receptor availability in MDMA users using $\left[{ }^{11} \mathrm{C}\right] \mathrm{MDL}$ 100907, a PET ligand that provides both high selectivity toward $5-\mathrm{HT}_{2 \mathrm{~A}}$ receptors and high signal-to-noise ratio (Lundkvist et al, 1996a).

A group of adult, chronic, and current MDMA recreational users, devoid of psychiatric conditions and a group of matched healthy controls, underwent a 2-week period of monitored abstinence before scans with $\left.{ }^{[11} \mathrm{C}\right] \mathrm{DASB}$ and $\left[{ }^{11} \mathrm{C}\right] \mathrm{MDL} 100907$. We hypothesized that, compared with control subjects, MDMA users would display lower $\left[{ }^{11} \mathrm{C}\right] \mathrm{DASB}$ and higher $\left[{ }^{11} \mathrm{C}\right] \mathrm{MDL} 100907$ binding.

\section{SUBJECTS AND METHODS}

All procedures were approved by the Institutional Review Board at the New York State Psychiatric Institute. Informed consent was obtained for all subjects after a complete description of study procedures.

MDMA using subjects were required to have used ecstasy at least 15 times during their lifetime and to have used MDMA regularly during at least 12 months before enrollment. Occasional recreational use of substances other than MDMA was permitted. Subjects remained abstinent from all drugs for 2 weeks before PET scanning. MDMA use was ascertained by subject report, evaluated by the Psychiatric Research Interview for Substance and Mental Disorders (PRISM) (Hasin et al, 1996) and/or Structured Clinical Interview for DSM-IV Disorders (SCID) (First et al, 1996). Exclusion criteria included any other lifetime axis I disorder as assessed with the PRISM and/or SCID, including present substance abuse or dependence, other than alcohol or nicotine abuse or dependence, or cannabis past abuse; pregnancy or lactation, medical conditions, and presence of metallic objects in the body precluding MRI scan. Abstinence from all drugs for at least 2 weeks before PET scanning was required and monitored with twice weekly urine toxicology and confirmed again on the day of the PET scan. The use of MDMA during the previous 3 months was confirmed by hair analysis.

Healthy control subjects were matched by age, ethnicity, and gender. Inclusion/exclusion criteria were the same as for MDMA subjects, except no DSM-IV Axis I diagnoses were allowed, including any substance abuse or dependence.

$\left[{ }^{11} \mathrm{C}\right] \mathrm{MDL} 100907$ and $\left[{ }^{11} \mathrm{C}\right] \mathrm{DASB}$ were prepared as previously described (Lundkvist et al, 1996b; Wilson et al, 2000). Both PET scans with $\left[{ }^{11} \mathrm{C}\right] \mathrm{MDL} 100907$ and $\left[{ }^{11} \mathrm{C}\right]$ DASB were acquired on the same day whenever possible, in order to avoid a second catheter placement. A polyurethane head immobilization system was used (Soule Medical, Tampa, FL) to reduce head motion during scanning. For both compounds, the maximal injected dose was $20 \mathrm{mCi}$. PET imaging was performed on the ECAT EXACT HR + (Siemens Medical Systems, Knoxville, TN). Following completion of a transmission scan $(10 \mathrm{~min})$, the radiotracer was administered as an i.v. bolus over $45 \mathrm{~s}$. Emission data were collected in the 3D mode for 90 and 100 min for $\left[{ }^{11} \mathrm{C}\right]$ MDL 100907 and $\left[{ }^{11} \mathrm{C}\right] \mathrm{DASB}$, respectively. Arterial input function was measured as previously described (Abi-Dargham et al, 2000). MRI scans for all subjects were acquired on a GE $1.5 \mathrm{~T}$ Signa Advantage system (GE Healthcare, Milwaukee, WI).

Images were reconstructed by filtered-backprojection to a $128 \times 128 \times 63$ matrix (voxel size of $1.7 \times 1.7 \times 2.4 \mathrm{~mm}^{3}$ ) with attenuation correction using the transmission data and a Shepp 0.5 filter. Images were then processed with the image analysis software MEDx (Medical Numerics, Germantown, MD). All frames were realigned to a frame of reference, using the realignment tool in the SPM2 software package and were co-registered to the individual MRIs by maximization of mutual information.

The primary analysis of this study was a region of interest (ROI)-based analysis. ROI boundaries were drawn on each individual $\mathrm{MR}$ image according to previously described criteria (Abi-Dargham et al, 2000). ROI time activity curves 
were analyzed using a two-tissue compartment model (2TCM) with arterial input function. The total regional distribution volume $\left(V_{\mathrm{T}}, \mathrm{ml} / \mathrm{cm}^{3}\right)$, defined as the ratio of the total tracer concentration in the region to the metabolite corrected plasma concentration at equilibrium, was derived from the rate constants. Binding potential $\left(\mathrm{BP}_{\mathrm{ND}}\right)$ was estimated in each ROI according to:

$$
\mathrm{BP}_{\mathrm{ND}}=V_{\mathrm{T}}(\mathrm{ROI}) / V_{\mathrm{T}}(\text { cerebellum })-1
$$

$\mathrm{BP}_{\mathrm{ND}}$ is equivalent to $f_{\mathrm{ND}} B_{\mathrm{MAX}} / K_{\mathrm{D}}$ where $B_{\mathrm{MAX}}(\mathrm{nM})$ is the concentration of sites available for binding, $K_{\mathrm{D}}(\mathrm{nM})$ is the equilibrium dissociation constant of the radiotracer for the sites, and $f_{\mathrm{ND}}$ is the free fraction in the nondisplaceable compartment. Analyses were performed on the Matlab programming platform (Mathworks, Natick, MA). ROI time activity curves were also analyzed using a simplified region of reference model (SRTM) a method that does not use the arterial input function (Gunn et al, 1997).

Results from the ROI analyses were confirmed and illustrated with a voxel-wise analysis. Individual $\mathrm{BP}_{\mathrm{ND}}$ maps were generated for each subject and were nonlinearly transformed into a common template space, by fitting each voxel to a one-tissue compartment (1TC) analysis. Individual $\mathrm{BP}_{\mathrm{ND}}$ maps were normalized to a $\mathrm{T} 1$-weighted, single subject MRI template. Data were smoothed with a $12-\mathrm{mm}$ FWHM Gaussian kernel. Group means were compared using a two-group $t$ statistic.

Table I Group Demographics, Scan Parameters, and Binding Potentials

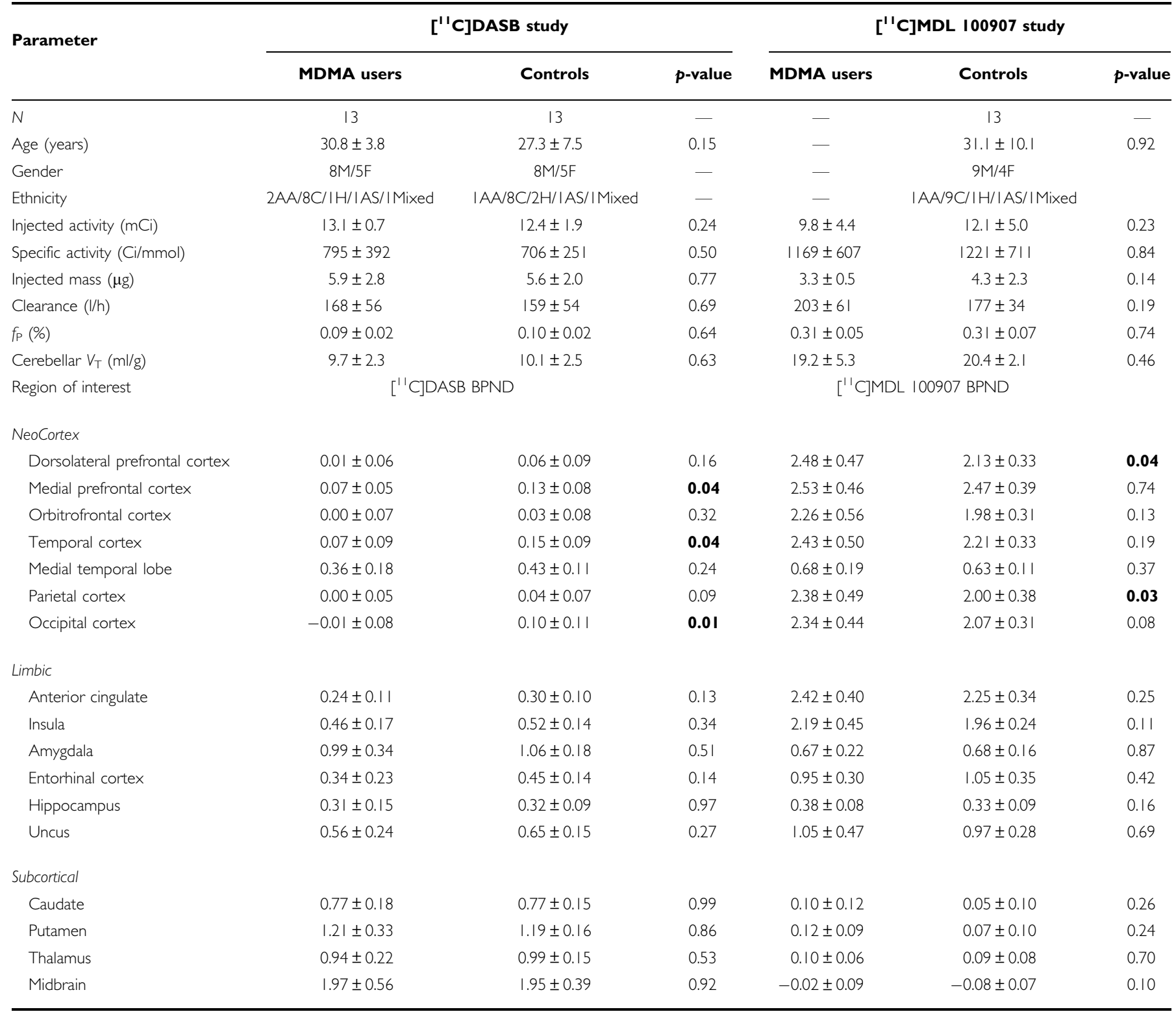

$f_{\mathrm{P}}$ refers to the plasma-free fraction; $V_{T}$ is the total regional distribution volume of the reference region.

While $n=13$ healthy controls were matched to the ecstasy group for each tracer, only eight of them were scanned with both tracers, five in each control group were different between tracers.

Bold values indicate statistically significant between group difference. 
Group means are presented as average \pm SD. A linear mixed model across all regions, all cortical regions, and all subcortical subregions, respectively, with regional $\mathrm{BP}_{\mathrm{ND}}$ as the dependent variable and ROI as repeated measure, was performed to test for a global effect of MDMA use on $\mathrm{BP}_{\mathrm{ND}}$. A two-tailed probability value of 0.05 was selected as the significance level. Pairwise comparisons of marginal group means were also examined at the ROI level. Relationships between clinical parameters and $\mathrm{BP}_{\mathrm{ND}}$ were analyzed using Pearson correlation coefficients. Parameters analyzed were number of lifetime sessions, total duration of use, frequency of use, and length of abstinence before the scan.

\section{RESULTS}

Fourteen MDMA users were recruited into this study. One subject was excluded after the scans, due to a technical problem during the $\left[{ }^{11} \mathrm{C}\right] \mathrm{MDL} 100907$ scan. Thus, 13 MDMA users were included in the final analysis. A total of 18 healthy controls were scanned, out of which 8 underwent both $\left[{ }^{11} \mathrm{C}\right] \mathrm{DASB}$ and $\left[{ }^{11} \mathrm{C}\right] \mathrm{MDL} 100907$ scans. Five subjects underwent only the $\left[{ }^{11} \mathrm{C}\right] \mathrm{DASB}$ or $\left[{ }^{11} \mathrm{C}\right] \mathrm{MDL}$ 100907 scan.

MDMA users were young adults of both genders and predominantly Caucasians (Table 1) and showed a range of severity and duration of ecstasy use. Total lifetime sessions of MDMA use was moderate (10-99) to severe $(>100)$ (Parrott et al, 2002), with a mean of 142, median of 50, and range of 15-1050 sessions. Total duration of use was 93 months (mean), with median of 84 and range of 4-216 months. Frequency of use was 1.9 sessions per month (mean), with median of 0.8 and range of $0.3-6.3$ sessions per month. Abstinence period before the PET scans was 5.7 weeks (mean), with median of 8 and range of 2-8 weeks.

Among MDMA users, six were nicotine smokers and seven were nonsmokers (among the controls, only one was a smoker). All MDMA subjects were using alcohol regularly and two met criteria for alcohol dependence or abuse, respectively. Most MDMA subjects (10/13) had used cannabis regularly. Five out of 13 MDMA subjects had > 10 lifetime exposures to hallucinogens (lysergic acid diethylamide, mushrooms, psilocybin, and mescaline). MDMA subjects with $>10$ lifetime exposures to other illegal drugs included cocaine, $n=1$; ketamine, $n=1$; amphetamine, $n=3$; and opiates, $n=1$. All subjects had negative urine toxicologies for any substance of abuse on the day of the PET scan.

There were no significant group differences in demographic or scan variables (Table 1). As expected from the regional distribution of SERT in the human brain (Laruelle et al, 1988), $\left[{ }^{11} \mathrm{C}\right] \mathrm{DASB}$ specific binding was high in subcortical regions and very low in cortical regions (Figure 1).

MDMA users exhibited lower $\left[{ }^{11} \mathrm{C}\right] \mathrm{DASB} \mathrm{BP}_{\mathrm{ND}}$ compared with healthy control subjects when all regions were analyzed together $(\mathrm{F}=27.07, p<0.001)$, when all cortical regions were analyzed $(\mathrm{F}=25.65, p<0.001)$, but not when subcortical regions were analyzed $(\mathrm{F}=1.99, p=0.16)$. In each case, the region by diagnosis interaction was not significant.

When individual regions were examined, $\left[{ }^{19} \mathrm{C}\right] \mathrm{DASB}$ $\mathrm{BP}_{\mathrm{ND}}$ was significantly lower in MDMA users compared with healthy control subjects in medial prefrontal cortex,

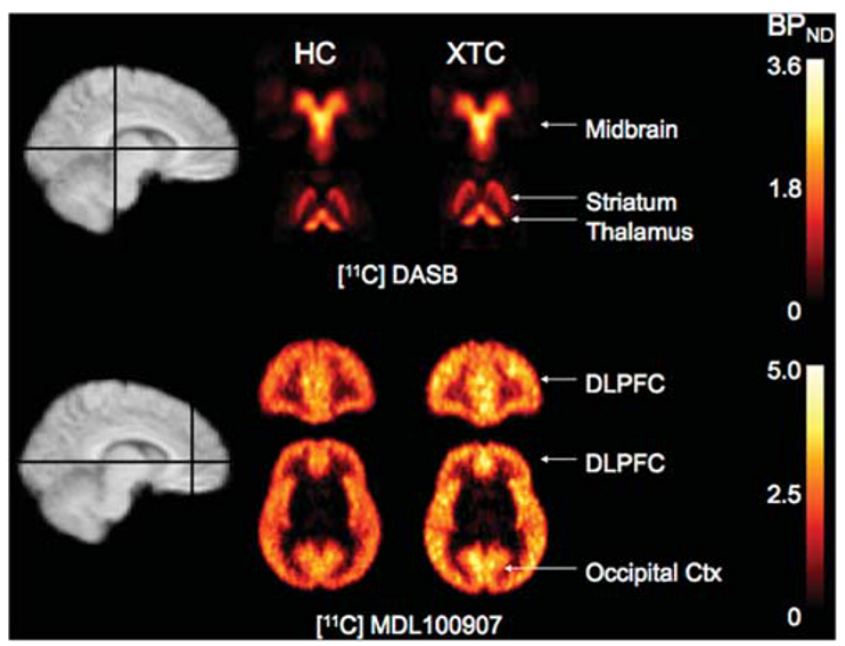

Figure I Parametric map of $\mathrm{BP}_{\mathrm{ND}}$ of the serotonin transporter ligand $\left[{ }^{\prime \prime} \mathrm{C}\right] \mathrm{DASB}$ (top) and the 5-HT2A receptor $\left[{ }^{1 /} \mathrm{C}\right] \mathrm{MDL} 100907$ (bottom) computed for 13 MDMA users (XTC, right column) and 13 healthy control subjects (HC, middle column). Individual $\mathrm{BP}_{\mathrm{ND}}$ maps were generated for each subject and were nonlinearly transformed into a common template space. The co-registered structural MRls with lines indicating the planes of view (coronal and transverse) on the left are the average from four subjects. Displayed are the regions of highest ligand binding. Regions of high [ ' C]DASB binding are subcortical (striatum, thalamus, midbrain), while to signal is very faint in cortical regions. The reverse is true for $\left[{ }^{\prime \prime} \mathrm{C}\right] \mathrm{MDL}$ 100907. [ " C]MDL 100907 binding is higher in cortical regions, and $\left[{ }^{\prime \prime} \mathrm{C}\right] \mathrm{MDL} 100907$ specific binding is barely detectable in subcortical regions.

occipital cortex, and temporal cortex (Table 1; Figure 2), though none of the pairwise regional comparisons survive correction for multiple comparisons. SERT-specific binding could not be detected in several cortical regions in MDMA users (Table 1). Similar results were obtained using SRTM as the analytical method. Results from the ROI analysis were confirmed and illustrated by the SPM analysis (Figure 3).

There were no correlations between availability of SERT and any clinical parameters (including duration of abstinence) that reached statistical significance. $\left[{ }^{11} \mathrm{C}\right] \mathrm{DASB} \mathrm{BP}_{\mathrm{ND}}$ in DLPFC and parietal cortex showed a trend to negative correlation with lifetime total uses of MDMA $(r=-0.46$, $p=0.12$ and $r=-0.46, p=0.11)$. Duration of MDMA use was negatively related to $\left[{ }^{11} \mathrm{C}\right] \mathrm{DASB} \mathrm{BP}_{\mathrm{ND}}$ in occipital $(r=-0.47, \quad p=0.12)$ and parietal cortex $(r=-0.44$, $p=0.14)$. None of these correlations were significant.

Also for $\left[{ }^{11} \mathrm{C}\right] \mathrm{MDL}$ 100907, there were no significant group differences in demographic or scan variables (Table 1). As expected from the known distribution of 5- $\mathrm{HT}_{2 \mathrm{~A}}$ receptors in the human brain (Laruelle and Maloteaux, 1989), $\left[{ }^{11} \mathrm{C}\right] \mathrm{MDL}$ 100907 specific binding was high in cortical regions and very low in subcortical regions (Figure 1).

MDMA users exhibited higher $\left[{ }^{11} \mathrm{C}\right] \mathrm{MDL} 100907 \mathrm{BP}_{\mathrm{ND}}$ compared with healthy control subjects when all regions were analyzed together $(\mathrm{F}=12.73, p<0.001)$, when all cortical regions were analyzed $(\mathrm{F}=14.55, p<0.001)$, and when only subcortical regions were analyzed $(\mathrm{F}=7.38$, $p=0.007)$. There was no significant region by diagnosis interaction. $\left[{ }^{11} \mathrm{C}\right] \mathrm{MDL} \quad 100907 \quad \mathrm{BP}_{\mathrm{ND}}$ was significantly higher in MDMA users compared with healthy control 

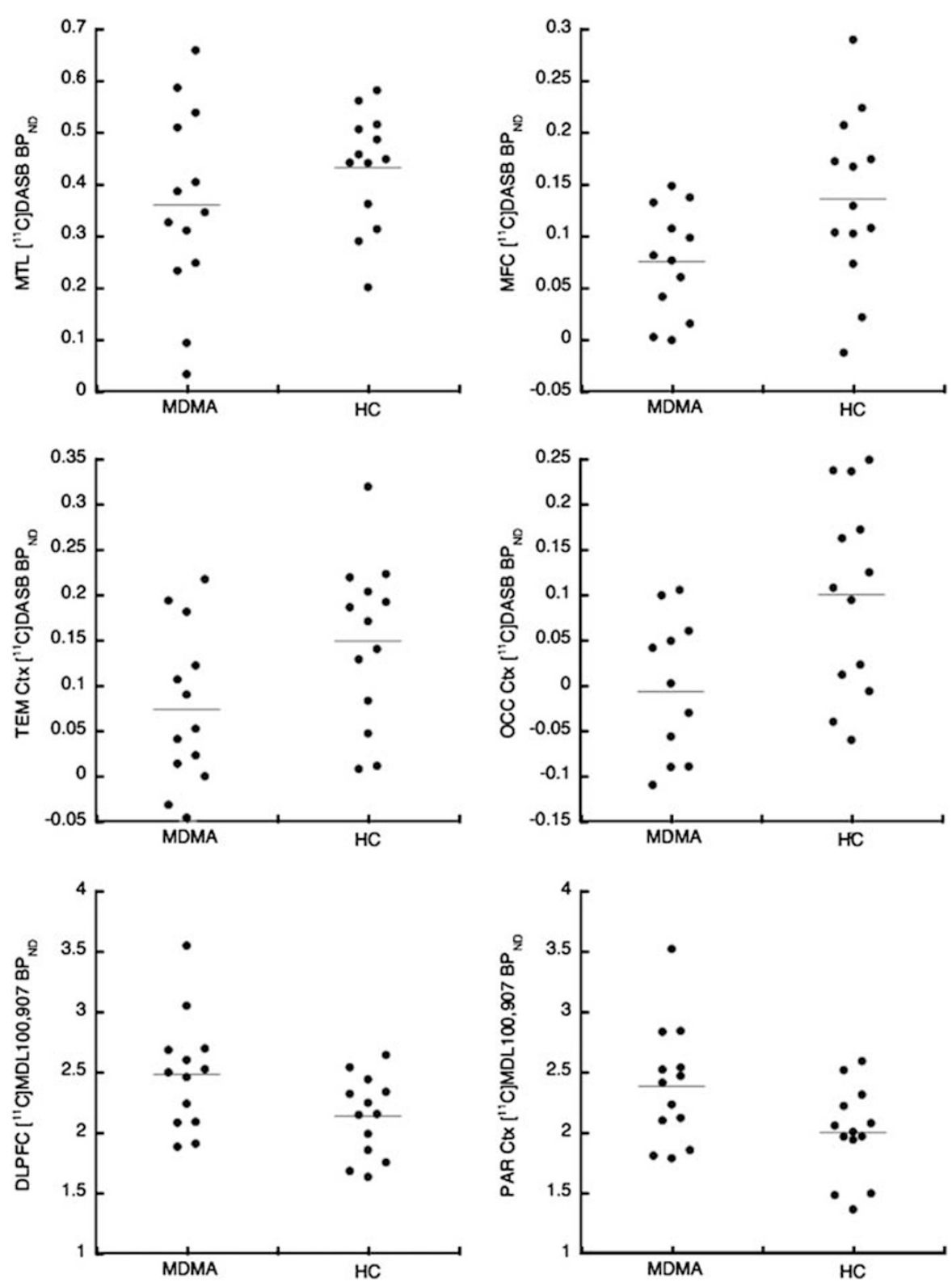

Figure 2 Scattergrams of [ ' C]DASB (two top rows) and [ ' C]MDL 100907 (lower row) BP ${ }_{\text {ND }}$ values in MDMA users and control subjects in selected cortical regions: medial temporal lobe (MTL), medial frontal cortex (MFC), temporal cortex (TEMP), occipital cortex (OCC), dorsolateral prefrontal cortex (DLPFC), and parietal cortex (PAR).

subjects in dorsolateral prefrontal cortex and parietal cortex, although these did not survive correction for multiple comparisons (Table 1; Figure 2). Similar results were obtained using SRTM as the analytical method. Results from the ROI analysis were confirmed and illustrated by the SPM analysis (Figure 3).

No correlations were observed between availability of $5-\mathrm{HT}_{2 \mathrm{~A}}$ receptor and any of the clinical parameters of ecstasy use history, including duration of abstinence. Among cortical regions, a trend to correlation was observed between the magnitude of difference in $\left[{ }^{11} \mathrm{C}\right] \mathrm{MDL} 100907$ binding between groups (higher for ecstasy users) and the difference in $\left[{ }^{11} \mathrm{C}\right] \mathrm{DASB}$ binding (lower for ecstasy users; $r^{2}=0.54, p=0.057$; Figure 4). The two medial regions (medial temporal lobe and medial prefrontal cortex) were the least affected on both parameters.

\section{DISCUSSION}

This study confirmed the results of recently published $\left[{ }^{11} \mathrm{C}\right] \mathrm{DASB}$ studies (Erritzoe et al, 2011; Kish et al, 2010; McCann et al, 2005, 2008), reporting that MDMA use is associated with significantly lower cortical SERT availability following a short period of abstinence. This study also revealed that postsynaptic $5-\mathrm{HT}_{2 \mathrm{~A}}$ receptors were upregulated in the regions where SERT was lower, an observation that might capture a compensatory upregulation of these receptors secondary to a state of 5-HT depletion.

The strengths of this study include the use of the most selective radiotracers currently available for SERT $\left(\left[{ }^{11} \mathrm{C}\right] \mathrm{DASB}\right)$ and $5-\mathrm{HT}_{2 \mathrm{~A}}$ receptors $\left(\left[{ }^{11} \mathrm{C}\right] \mathrm{MDL} 100907\right)$, and a fully quantitative approach to $\mathrm{BP}_{\mathrm{ND}}$ derivation that included measurement of arterial input function. While 


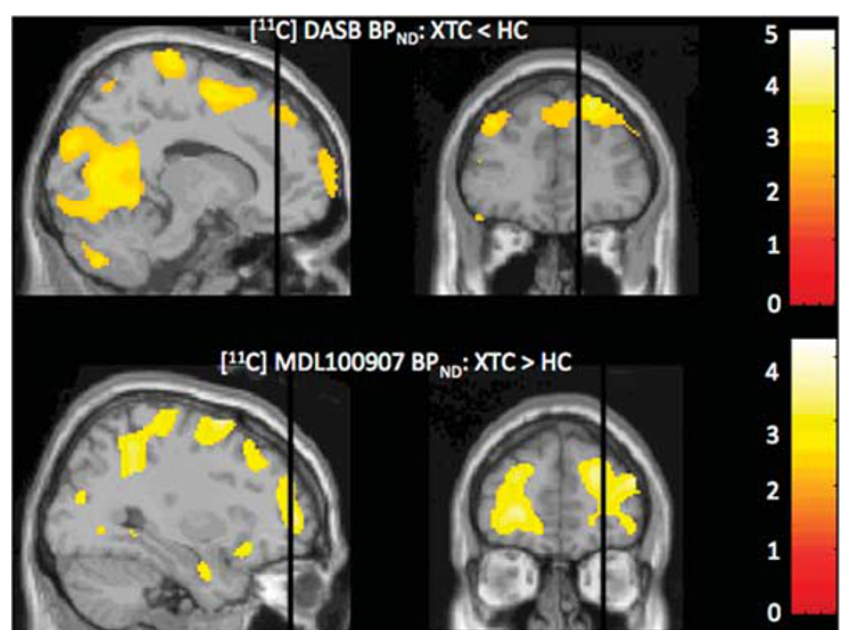

Figure 3 Voxel-wise group mean comparisons of $\left[{ }^{1} \mathrm{C}\right] \mathrm{MDL} 100907$ and $\left[{ }^{\prime \prime} C\right] D A S B B_{N D}$ between MDMA (XTC) and $\mathrm{HC}$ subjects. Each subject's PET data were analyzed using a ITC model for both ligands. Individual $\mathrm{BP}_{\mathrm{ND}}$ maps were normalized to a $\mathrm{TI}$-weighted, single subject MRI template. Data were smoothed with a 12-mm FWHM Gaussian kernel. Group means were compared using a two-group $t$ statistic. There were widespread clusters of voxels in cortical regions reaching trend level difference for $\mathrm{XTC}<\mathrm{HC}$ with [ ' $\mathrm{C}] \mathrm{DASB} \mathrm{BP}_{\mathrm{ND}}$ (top: occipital, parietal, and prefrontal cortices, $p=0.08$, FDR corrected) and for XTC $>\mathrm{HC}$ with $\left[{ }^{\prime \prime} \mathrm{C}\right] \mathrm{MDL} 100907 \mathrm{BP}_{\mathrm{ND}}$ (bottom: parietal and dorsolateral prefrontal cortex, $p=0.06$, FDR corrected) that, in general coincided with the ROI analysis results. The display threshold was set at $p \leqslant 0.01$. The vertical line in each view shows the slice level of the other view for that ligand. The color scale represents the values of the $t$ statistic.

$\mathrm{BP}_{\mathrm{ND}}$ can be derived without an arterial input function, the use of this outcome measure to assess between group differences implies the assumption that the nonspecific binding does not differ between the groups. In this study, this assumption was verified (no between group differences were observed in cerebellar $V_{\mathrm{T}}$; Table 1 ), which validates the use of $\mathrm{BP}_{\mathrm{ND}}$ as an outcome measure for between group comparison.

The weaknesses of this study include the relatively low number of subjects and the fact that MDMA users also used other drugs, mainly alcohol and cannabis. Previous work established that alcohol abuse or dependence per se is not associated with alterations of 5-HT parameters measured in vivo (Erritzoe et al, 2009, 2010; Martinez et al, 2009). To our knowledge, no studies have yet demonstrated the integrity of these 5-HT parameters in cannabis users. Subjects included in this study also occasionally used other drugs. To find subjects with a decade of exposure to MDMA and no exposure to alcohol, cannabis, or other drugs is extremely difficult. To control for the use of other drugs, some studies of SERT availability have included a control group of polysubstance users with no exposure to MDMA, and failed to report alterations of SERT in this group (Buchert et al, 2003; Selvaraj et al, 2009). Some studies have demonstrated lower SERT binding in users of methamphetamine (Kish et al, 2009; Sekine et al, 2006). Thus, the possibility that other drugs might have contributed to the alterations of the 5-HT parameters observed in the MDMA users cannot be strictly ruled out, but is unlikely given the small number of subjects with a history of methamphetamine use in this sample $(n=3)$.

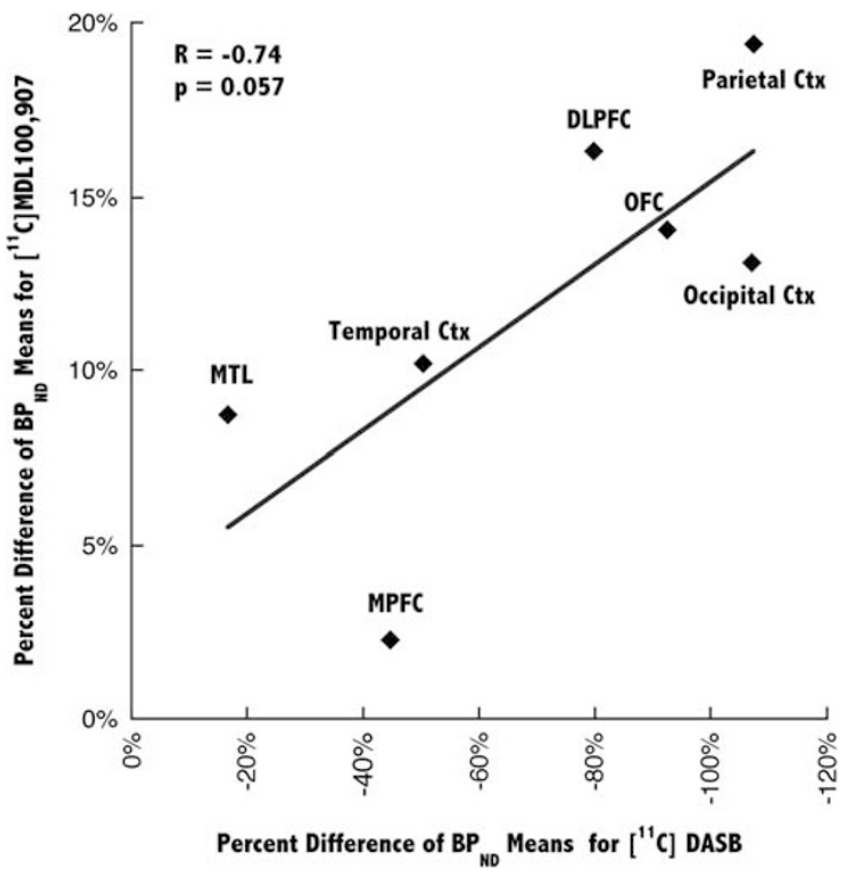

Figure 4 Association between the percent difference in group means for the two ligands in the seven cortical regions (DLPFC, dorsolateral prefrontal cortex; MPFC, medial prefrontal cortex; OFC, orbiotfrontal cortex; occipital cortex, parietal cortex, temporal Ctx, MTL, medial temporal lobe). For each ligand and each region, data are expressed as percent change compared with controls. $R$ is the Pearson product moment correlation coefficient; the $p$-value is for a two-tailed t-test with $5 \mathrm{df}$. Cortical regions with the lowest [ ' ${ }^{\prime}$ C]DASB BP ( $x$ axis) showed the highest in [ [ ' C]MDL 100907 BP. This was significant at trend level. Interestingly, the two medial regions (MPFC and MLT) showed the smallest change, presumably due to relatively shorter axonal length.

In this study, current MDMA abusers showed lower cortical SERT binding compared with controls. The monitored period of abstinence before the scans was relatively short (2 weeks), raising concerns that residual binding of MDMA to the SERT might have contributed to the reduced SERT availability. However, the regional specificity of this effect makes this explanation unlikely: While the finding was global in the cortical regions, it was more pronounced in the medial prefrontral, temporal, and occipital cortex and when comparing cortical to subcortical regions.

It is theoretically conceivable that a decreased 5-HT function in the cortex might be a predisposing factor to the use of MDMA and that the use is a consequence rather than a cause of 5-HT dysfunction. While this study cannot refute this hypothesis, the experimental evidence in animals of the selective neurotoxicity of MDMA toward 5-HT neurons supports the proposition that sustained MDMA exposure is directly responsible for the alterations of 5-HT parameters observed in this study.

Given the clinical and geographic heterogeneity of the MDMA user populations studies, it is remarkable that 5 out of 5 studies, including this one, performed with $\left[{ }^{11} \mathrm{C}\right] \mathrm{DASB}$ in current (ie recently abstinent) MDMA users showed lower SERT availability in neocortical regions (Table 2). The four other studies have also reported alterations in the hippocampus. Conversely, all studies but one showed unaltered levels in the striatal regions or in the thalamus, 
Table $2\left[{ }^{\prime \prime} C\right] D A S B$ Studies in Current $(n=5)$ and Former $(n=1)$ MDMA Abusers

\begin{tabular}{|c|c|c|c|c|c|c|c|c|}
\hline Study & Catchement area & $n$ & MDMA users & Cortex & Limbic & Striatum & Thalamus & Midbrain \\
\hline McCann et al (2005) & Baltimore, USA & 23 & Current & Lower & Lower & No difference & Lower & No difference \\
\hline McCann et al (2008) & Baltimore, USA & 16 & Current & Lower & Lower & No difference & No difference & No difference \\
\hline Kish et al (20।0) & Toronto, CA & 49 & Current & Lower & Lower & No difference & No difference & No difference \\
\hline Erritzoe et al (201 I) & Copenhagen, DK & 14 & Current & Lower & Lower & Lower & No difference & No difference \\
\hline This study & New York, USA & 13 & Current & Lower & No difference & No difference & No difference & No difference \\
\hline
\end{tabular}

Lower/no difference refers to [ ' C]DASB binding in MDMA users compared with healthy controls.

and all studies reported unaltered levels in the midbrain. The low expression of SERT in the cortex (Figure 1) and the resulting small and noisy specific signal recorded with $\left[{ }^{11} \mathrm{C}\right] \mathrm{DASB}$ in this region (Frankle et al, 2006) makes this body of results particularly impressive. If anything, alterations of SERT in the cortex should be more difficult to detect than in the SERT-rich regions of the thalamus, midbrain, and striatum. Studies with higher affinity SERT radiotracer such as $\left[{ }^{11} \mathrm{C}\right] \mathrm{AFM}$ might be useful to further assess these findings (Huang et al, 2002).

These PET findings are entirely consistent with the preclinical literature that showed that vulnerability of 5-HT neurons to MDMA is related to the axonal length (Molliver et al, 1990), making 5-HT neurons with the longest axons, innervating the cortex more susceptible to MDMA damage compared with the neurons innervating subcortical structures. Even within cortical regions, a difference is observed between the medial and dorsal regions, with dorsal regions associated with longest axonal lengths being more affected than the medial regions (Figure 4).

The only $\left[{ }^{11} \mathrm{C}\right] \mathrm{DASB}$ study that failed to detect changes in MDMA users is the study of Selvaraj et al (2009), who investigated $\left[{ }^{11} \mathrm{C}\right] \mathrm{DASB}$ in 12 former MDMA abusers (last use $>1$ year before the scan). This finding suggests that the lower SERT availability observed in current users might be reversible. However, caution should be used before adopting this conclusion. As mentioned earlier, $\left[{ }^{11} \mathrm{C}\right] \mathrm{DASB}$ measurement in the cortex is noisy, and the Selvaraj et al (2009) study did not include a positive group of current users. Thus, more work, including longitudinal studies of abstinence, is needed to test the reversibility of these changes. We were not able to demonstrate any correlation between length of abstinence and SERT or $5-\mathrm{HT}_{2 \mathrm{~A}}$ binding, but a relatively small sample size and a small range of duration of abstinence compared with other studies that found indicators of reversibility may have been limiting.

PET $\left[{ }^{11} \mathrm{C}\right] \mathrm{DASB}$ studies per se cannot ascertain if the lower SERT availability observed in the cortical regions of current MDMA users corresponds to a loss of these terminals due to the neurotoxic effect of the drug or a functional downregulation of SERT expression as a homeostatic reaction to the repeated MDMA exposures, or some combination of both factors.

To our knowledge, this is the first study to evaluate $5-\mathrm{HT}_{2 \mathrm{~A}}$ receptors in recent MDMA users with PET and a truly selective $5-\mathrm{HT}_{2 \mathrm{~A}}$ receptor PET ligand, $\left[{ }^{11} \mathrm{C}\right] \mathrm{MDL}$ 100907. MDMA users showed higher $5-\mathrm{HT}_{2 \mathrm{~A}}$ receptor availability compared with control subjects in the cortex. Initial findings from SPECT studies performed with [ $\left.{ }^{123} \mathrm{I}\right] \mathrm{R} 93274$ suggested a complex effect of MDMA on $5-\mathrm{HT}_{2 \mathrm{~A}}$ receptors dependent on duration of abstinence, with $5-\mathrm{HT}_{2 \mathrm{~A}}$ receptor availability lower and higher in current and former MDMA users, respectively (Reneman et al, 2002). Because of the low signal-to-noise ratio of $\left[{ }^{123} \mathrm{I}\right] \mathrm{R} 93274$ (Abi-Dargham et al, 1997), confirmation with better ligands currently available was necessary. Recently, Erritzoe et al (2011) reported no difference in $5-\mathrm{HT}_{2 \mathrm{~A}}$ receptors measured with $\left[{ }^{18} \mathrm{~F}\right]$ altanserin in the cortical regions of current MDMA users. Compared with $\left[{ }^{11} \mathrm{C}\right] \mathrm{MDL} 100907,\left[{ }^{18} \mathrm{~F}\right]$ altanserin is less selective for $5-\mathrm{HT}_{2 \mathrm{~A}}$ receptors, as it displays nonnegligible affinity for $5-\mathrm{HT}_{2 \mathrm{C}}$ receptors (Kristiansen et al, 2005). Yet, this factor is unlikely to account for these different results (Kristiansen et al, 2005). More likely, the more prevalent use of hallucinogens in the Danish study might explain the difference in the findings, as these drugs are $5-\mathrm{HT}_{2 \mathrm{~A}}$ receptor agonists and, as such, are expected to downregulate $5-\mathrm{HT}_{2 \mathrm{~A}}$ receptors (Pranzatelli, 1991).

A number of animal studies showed that chronic 5-HT depletion leads to upregulation of $5-\mathrm{HT}_{2 \mathrm{~A}}$ receptors, supporting the hypothesis that $5-\mathrm{HT}_{2 \mathrm{~A}}$ receptor upregulation observed in this study might be secondary to sustained 5-HT depletion (Cahir et al, 2007; Heal et al, 1985). The higher $\left[{ }^{11} \mathrm{C}\right] \mathrm{MDL} 100907$ binding was observed in the neocortex, that is, in the same region where SERT density was lower. Moreover, within the cortex, a relationship (significant at trend level) was observed between lower $\left[{ }^{11} \mathrm{C}\right] \mathrm{DASB}$ binding and higher $\left[{ }^{11} \mathrm{C}\right] \mathrm{MDL} 100907$ binding (Figure 4), a relationship that might be driven by impact of axonal length of 5-HT neurons vulnerability to MDMA. Thus, the data converged to indicate the existence of an alteration in both presynaptic and postsynaptic 5-HT markers in the cortex, alterations consistent with a state of decreased 5-HT tone and in line with the animal data showing the vulnerability of cortical 5-HT terminals to repeated MDMA exposure. It remains unclear if the alterations observed in this study represent reversible functional adaptations, potentially irreversible neurotoxic changes, or some combination of both factors.

The result from this study confirms, in an independent cohort, that current MDMA exposure is associated with lower SERT availability in cortical but not subcortical regions. This study also reveals that upregulation of $5-\mathrm{HT}_{2 \mathrm{~A}}$ receptors is found in cortical areas of these subjects, suggesting the existence of a chronic state of lower 5-HT tone in these subjects. Together with the animal literature, the most direct interpretation of these studies is that 
repeated exposure to MDMA, even at moderate levels, leads to changes in serotonin parameters in the most vulnerable 5-HT neurons, that is, 5 -HT neurons innervating the cortex. The reversibility of these changes upon sustained abstinence is suggested by several studies (Buchert et al, 2006; Erritzoe et al, 2011; Kish et al, 2010; McCann et al, 2005; Selvaraj et al, 2009), supporting temporary downregulation of SERT and upregulation of $5-\mathrm{HT}_{2 \mathrm{~A}}$ in response to acute 5-HT depletion, but remains to be firmly established. The functional implication of these changes are unknown, but it is conceivable that alterations in mood, cognition, and impulse control associated with these changes might contribute to sustain the MDMA-taking behavior.

\section{ACKNOWLEDGEMENTS}

We acknowledge the excellent technical assistance of Elizabeth Hackett, Sung-A Bae, and John Castrillon.

\section{DISCLOSURE}

This research was carried out at New York State Psychiatric Institute/Columbia University Medical Center under a grant \# RO1 DA015806-02 from the National Institute on Drug Abuse (NIDA). The following authors declare that except from income received from their primary employer, no financial support has been received from any individual or corporate entity over the past 3 years for research or professional services and there are no personal financial holdings that could be perceived as constituting a conflict of interest: Drs Urban, Talbot, Hart, Xu, and Laruelle. Over the past 3 years, Dr Frankle has received compensation as a consultant for ONO Pharmaceuticals and Sunovion Pharmaceuticals; Dr Girgis has received research support from Lilly Pharmaceuticals; Dr Kegeles has received research grants from Amgen and Pfizer; Dr Slifstein has received compensation as a consultant for Amgen and GlaxoSmithKline, and research support from Pierre Fabre; and $\mathrm{Dr}$ Abi-Dargham has received compensation as a speaker and consultant for Bristol-Myers Squibb-Otsuka, as a consultant for Bohringer-Engelheim, Lundbeck, Sunovion, Otsuka, Shire, Pfizer, Merck, and research support from GlaxoSmithKline and Forest Pharmaceuticals.

\section{REFERENCES}

Abi-Dargham A, Martinez D, Mawlawi O, Simpson N, Hwang DR, Slifstein $\mathrm{M}$ et al (2000). Measurement of striatal and extrastriatal dopamine D1 receptor binding potential with [11C]NNC 112 in humans: validation and reproducibility. J Cereb Blood Flow Metab 20: 225-243.

Abi-Dargham A, Zea-Ponce Y, Terriere D, Al-Tikriti M, Baldwin R, Hoffer P et al (1997). Preclinical evaluation of [I-123]R93274 as a SPECT radiotracer for imaging serotonin 5-HT2A receptors. Eur J Pharmacol 321: 285-293.

Buchert R, Thomasius R, Nebeling B, Petersen K, Obrocki J, Jenicke L et al (2003). Long-term effects of 'ecstasy' use on serotonin transporters of the brain investigated by PET. J Nucl Med 44: 375-384.

Buchert R, Thomasius R, Petersen K, Wilke F, Obrocki J, Nebeling B et al (2006). Reversibility of ecstasy-induced reduction in serotonin transporter availability in polydrug ecstasy users. Eur J Nucl Med Mol Imaging 33: 188-199.

Cahir M, Ardis T, Reynolds GP, Cooper SJ (2007). Acute and chronic tryptophan depletion differentially regulate central 5-HT1A and 5-HT 2A receptor binding in the rat. Psychopharmacology (Berl) 190: 497-506.

Cohen RS (1995). Subjective reports on the effects of the MDMA ('ecstasy') experience in humans. Prog Neuropsychopharmacol Biol Psychiatry 19: 1137-1145.

de Win MM, Schilt T, Reneman L, Vervaeke H, Jager G, Dijkink S et al (2006). Ecstasy use and self-reported depression, impulsivity, and sensation seeking: a prospective cohort study. J Psychopharmacol 20: 226-235.

Erritzoe D, Frokjaer VG, Haahr MT, Kalbitzer J, Svarer C, Holst KK et al (2010). Cerebral serotonin transporter binding is inversely related to body mass index. Neuroimage 52: 284-289.

Erritzoe D, Frokjaer VG, Haugbol S, Marner L, Svarer C, Holst K et al (2009). Brain serotonin 2A receptor binding: relations to body mass index, tobacco and alcohol use. Neuroimage 46: 23-30.

Erritzoe D, Frokjaer VG, Holst KK, Christoffersen M, Johansen SS, Svarer C et al (2011). In vivo imaging of cerebral serotonin transporter and serotonin2A receptor binding in 3,4-methylenedioxymethamphetamine (MDMA or 'ecstasy') and hallucinogen users. Arch Gen Psychiatry 68: 562-576.

First MB, Spitzer RL, Gibbon M, Williams JBW (1996). Structured Clinical Interview for DSM-IV Axis I Disorders, Clinician Version (SCID-CV). American Psychiatric Press, Inc: Washington D.C.

Frankle WG, Huang Y, Hwang DR, Talbot PS, Slifstein M, Van Heertum $\mathrm{R}$ et al (2004). Comparative evaluation of serotonin transporter radioligands 11C-DASB and 11C-McN 5652 in healthy humans. J Nucl Med 45: 682-694.

Frankle WG, Slifstein M, Gunn RN, Huang Y, Hwang DR, Darr EA et al (2006). Estimation of serotonin transporter parameters with $11 \mathrm{C}-\mathrm{DASB}$ in healthy humans: reproducibility and comparison of methods. J Nucl Med 47: 815-826.

Gunn RN, Lammertsma AA, Hume SP, Cunningham VJ (1997). Parametric imaging of ligand-receptor binding in PET using a simplified reference region model. Neuroimage 6: 279-287.

Hasin DS, Trautman KD, Miele GM, Samet S, Smith M, Endicott J (1996). Psychiatric research interview for substance and mental disorders (PRISM): reliability for substance abusers. Am J Psychiat 153: 1195-1201.

Heal DJ, Philpot J, Molyneux SG, Metz A (1985). Intracerebroventricular administration of 5,7-dihydroxytryptamine to mice increases both head-twitch response and the number of cortical 5-HT2 receptors. Neuropharmacology 24: 1201-1205.

Houle S, Ginovart N, Hussey D, Meyer JH, Wilson AA (2000). Imaging the serotonin transporter with positron emission tomography: initial human studies with [11C]DAPP and [11C]DASB. Eur J Nucl Med 27: 1719-1722.

Huang Y, Hwang DR, Narendran R, Sudo Y, Chatterjee R, Bae SA et al (2002). Comparative evaluation in nonhuman primates of five PET radiotracers for imaging the serotonin transporters: [11C]McN 5652, [11C]ADAM, [11C]DASB, [11C]DAPA, and [11C]AFM. J Cereb Blood Flow Metab 22: 1377-1398.

Insel TR, Battaglia G, Johannessen JN, Marra S, De Souza EB (1989). 3,4-Methylenedioxymethamphetamine ('ecstasy') selectively destroys brain serotonin terminals in rhesus monkeys. J Pharmacol Exp Ther 249: 713-720.

Kish SJ, Fitzmaurice PS, Boileau I, Schmunk GA, Ang LC, Furukawa Y et al (2009). Brain serotonin transporter in human methamphetamine users. Psychopharmacology (Berl) 202: 649-661.

Kish SJ, Lerch J, Furukawa Y, Tong J, McCluskey T, Wilkins D et al (2010). Decreased cerebral cortical serotonin transporter binding in ecstasy users: a positron emission tomography/ [(11)C]DASB and structural brain imaging study. Brain 133: 1779-1797. 
Kristiansen H, Elfving B, Plenge P, Pinborg LH, Gillings N, Knudsen GM (2005). Binding characteristics of the 5-HT2A receptor antagonists altanserin and MDL 100907. Synapse 58: 249-257.

Laruelle M, Baldwin RM, Malison RT, Zea-Ponce Y, Zoghbi SS, Al-Tikriti $M$ et al (1993). SPECT imaging of dopamine and serotonin transporters with [123-I] $\beta$-CIT: pharmacological characterization of brain uptake in nonhuman primates. Synapse 13: 295-309.

Laruelle M, Maloteaux JM (1989). Regional distribution of pre- and post- synaptic markers in human brain. Acta Psychiatr Scand 80: $56-59$.

Laruelle M, Vanisberg M, Maloteaux J (1988). Regional and subcellular localization in human brain of [3H]paroxetine binding, a marker of serotonin uptake sites. Biol Psychiatry 24: 299-309.

Lundkvist C, Halldin C, Ginovart N, Nyberg S, Swahn CG, Carr AA et al (1996a). [11C]MDL 100907, a radioligand for selective imaging of 5-HT(2A) receptors with positron emission tomography. Life Sci 58: 187-192.

Lundkvist C, Halldin C, Ginovart N, Nyberg S, Swahn CG, Carr AA et al (1996b). [11C]MDL 100907, a radioligland for selective imaging of 5-HT(2A) receptors with positron emission tomography. Life Sci 58: PL 187-PL 192.

Martinez D, Slifstein M, Gil R, Hwang DR, Huang Y, Perez A et al (2009). Positron emission tomography imaging of the serotonin transporter and 5-HT(1A) receptor in alcohol dependence. Biol Psychiatry 65: 175-180.

McCann UD, Szabo Z, Scheffel U, Dannals RF, Ricaurte GA (1998). Positron emission tomographic evidence of toxic effect of MDMA ('Ecstasy') on brain serotonin neurons in human beings. Lancet 352: 1433-1437.

McCann UD, Szabo Z, Seckin E, Rosenblatt P, Mathews WB, Ravert HT et al (2005). Quantitative PET studies of the serotonin transporter in MDMA users and controls using [11C]McN5652 and [11C]DASB. Neuropsychopharmacology 30: 1741-1750.

McCann UD, Szabo Z, Vranesic M, Palermo M, Mathews WB, Ravert HT et al (2008). Positron emission tomographic studies of brain dopamine and serotonin transporters in abstinent (+/-)3,4-methylenedioxymethamphetamine ('ecstasy') users: relationship to cognitive performance. Psychopharmacology (Berl) 200: 439-450.

Molliver ME, Berger UV, Mamounas LA, Molliver DC, O’Hearn E, Wilson MA (1990). Neurotoxicity of MDMA and related compounds: anatomic studies. Ann NY Acad Sci 600: 649-661; discussion 661-644.

Parrott AC, Buchanan T, Scholey AB, Heffernan T, Ling J, Rodgers J (2002). Ecstasy/MDMA attributed problems reported by novice, moderate and heavy recreational users. Hum Psychopharmacol 17: 309-312.

Parsey RV, Kegeles LS, Hwang DR, Simpson N, Abi-Dargham A, Mawlawi $\mathrm{O}$ et al (2000). In vivo quantification of brain serotonin transporters in humans using $[11 \mathrm{C}] \mathrm{McN}$ 5652. J Nucl Med 41: $1465-1477$.
Pranzatelli MR (1991). Regulation of 5-HT2 receptors in rat cortex. Studies with a putative selective agonist and an antagonist. Biochem Pharmacol 42: 1099-1105.

Quednow BB, Kuhn KU, Hoppe C, Westheide J, Maier W, Daum I et al (2007). Elevated impulsivity and impaired decision-making cognition in heavy users of MDMA ('Ecstasy'). Psychopharmacology (Berl) 189: 517-530.

Reneman L, Booij J, de Bruin K, Reitsma JB, de Wolff FA, Gunning WB et al (2001). Effects of dose, sex, and long-term abstention from use on toxic effects of MDMA (ecstasy) on brain serotonin neurons. Lancet 358: 1864-1869.

Reneman L, Endert E, de Bruin K, Lavalaye J, Feenstra MG, de Wolff FA et al (2002). The acute and chronic effects of MDMA ('ecstasy') on cortical 5-HT2A receptors in rat and human brain. Neuropsychopharmacology 26: 387-396.

Ricaurte G, Bryan G, Strauss L, Seiden L, Schuster C (1985). Hallucinogenic amphetamine selectively destroys brain serotonin nerve terminals. Science 229: 986-988.

Ricaurte GA, DeLanney LE, Irwin I, Langston JW (1988). Toxic effects of MDMA on central serotonergic neurons in the primate: importance of route and frequency of drug administration. Brain Res 446: 165-168.

Scheffel U, Szabo Z, Mathews WB, Finley PA, Dannals RF, Ravert HT et al (1998). In vivo detection of short- and longterm MDMA neurotoxicity-a positron emission tomography study in the living baboon brain. Synapse 29: 183-192.

Schmidt CJ, Wu L, Lovenberg W (1986). Methylenedioxymethamphetamine: a potentially neurotoxic amphetamine analogue. Eur J Pharmacol 124: 175-178.

Sekine Y, Ouchi Y, Takei N, Yoshikawa E, Nakamura K, Futatsubashi $\mathrm{M}$ et al (2006). Brain serotonin transporter density and aggression in abstinent methamphetamine abusers. Arch Gen Psychiatry 63: 90-100.

Selvaraj S, Hoshi R, Bhagwagar Z, Murthy NV, Hinz R, Cowen P et al (2009). Brain serotonin transporter binding in former users of MDMA ('ecstasy'). Br J Psychiatry 194: 355-359.

Semple DM, Ebmeier KP, Glabus MF, O'Carroll RE, Johnstone EC (1999). Reduced in vivo binding to the serotonin transporter in the cerebral cortex of MDMA ('ecstasy') users. Br J Psychiatry 175: 63-69.

Szabo Z, Kao PF, Scheffel U, Suehiro M, Mathews WB, Ravert HT et al (1995). Positron emission tomography imaging of serotonin transporters in the human brain using [11C](+)McN5652. Synapse 20: 37-43.

Thomasius R, Zapletalova P, Petersen K, Buchert R, Andresen B, Wartberg L et al (2006). Mood, cognition and serotonin transporter availability in current and former ecstasy (MDMA) users: the longitudinal perspective. J Psychopharmacol 20: 211-225.

Wilson AA, Ginovart N, Schmidt M, Meyer JH, Threlkeld PG, Houle S (2000). Novel radiotracers for imaging the serotonin transporter by positron emission tomography: synthesis, radiosynthesis, and in vitro and ex vivo evaluation of (11)C-labeled 2-(phenylthio)araalkylamines. J Med Chem 43: 3103-3110. 